\title{
CRIANÇAS E A CONSTRUÇÃO DE LIMITES: NARRATIVAS DE MÃES E PROFESSORAS
}

\author{
Greicy Boness de Araujo* \\ Tania Mara Sperb"
}

\begin{abstract}
RESUMO. A questão dos limites na educação infantil tem se revelado uma dificuldade tanto para pais quanto para professores. Neste estudo foram investigadas as representações sociais de mães e professoras sobre limites no desenvolvimento infantil. O estudo contou com a participação de 14 mães e oito professoras de educação infantil de escolas particulares de Porto Alegre. A entrevista narrativa e a análise de conteúdo foram utilizadas como procedimentos de coleta de dados e análise. Os resultados indicaram que os limites são representados como fronteira a ser respeitada em prol da moralidade. A prática do diálogo é um recurso presente nas narrativas de mães e professoras, assim como a necessidade de tolerância. Ambas demonstram muitas dúvidas e culpas no tocante aos limites a serem impostos às crianças. As professoras atribuem a responsabilidade da falta de limites às famílias, já as mães não percebem a escola como uma aliada no processo de construção de limites.
\end{abstract}

Palavras-chave: práticas educativas, limite, narrativa.

\section{CHILDREN AND THE CONSTRUCTION OF LIMITS: MOTHERS AND TEACHERS' NARRATIVES}

\begin{abstract}
The question of limits in preschool education has been considered difficult for both parents and teachers. In this study mothers and teachers' social representations of limits in children's development were investigated. Fourteen mothers and eight preschool teachers of private schools of Porto Alegre participated in the study. The narrative interview and content analysis were used as procedures of data collection and analysis. The results indicated the representation of limits as frontiers to be respected for the sake of morality. The use of dialogue as a resource was cited by mothers and teachers in their narratives, as well as the need for tolerance. However, both also expressed many doubts, guilt and insecurity which reflect in the development of children's limits. While teachers attribute the responsibility of a lack of limits to the families mothers do not perceive the school as an ally in the process of limits construction.
\end{abstract}

Key words: Childrearing practices, limit, narrative.

\section{NIÑOS Y CONSTRUCCIÓN DE LÍMITES: RELATOS DE MADRES Y MAESTRAS}

RESUMEN. El tema de los límites en la educación infantil se ha revelado como una dificultad para padres y maestros. En este estudio fueron investigadas las representaciones sociales de madres y maestras sobre límites en el desarrollo infantil. El estudio contó con la participación de catorce madres y ocho maestras de educación primaria de escuelas particulares de Porto Alegre. La entrevista narrativa y el análisis de los contenidos fueron utilizados como procedimientos de colecta de datos y análisis. Los resultados indicaron que los límites son representados como frontera a ser respetada en aras de la moralidad. El uso del diálogo es un recurso presente en los relatos de madres y maestras, así como la importancia y necesidad de tolerancia. Madres y maestras muestran dudas y culpas que repercuten en el desarrollo de límites en los niños. Las maestras atribuyen la responsabilidad por la falta de límites a las familias. Por otro lado, las familias no ven a la escuela como una aliada en el proceso de construcción de límites.

Palabras-clave: Desarrollo infantil, límites, narrativas.

\footnotetext{
* Psicóloga, Mestre em Psicologia. Doutoranda em Psicologia pela Universidade Federal do Rio Grande do Sul.

\# Psicóloga, Phd em Psicologia do Desenvolvimento. Professora colaboradora do Programa de Pós-Graduação em Psicologia da Universidade Federal do Rio Grande do Sul.
} 
Questões econômicas e sociais como o processo de industrialização, a conquista dos direitos da mulher e sua participação crescente no mercado de trabalho têm gerado mudanças significativas nas configurações familiares, nas relações entre crianças e adultos e nas práticas educacionais. Estratégias educativas consideradas adequadas em épocas anteriores são questionadas na atualidade. Wagner, Predebon e Falcke (2005) salientam que novos padrões, valores e modelos de relação são estabelecidos entre pais e filhos, permeados pelas expectativas e ideais sociais. As novas exigências sociais estabelecem como ideal a independência, a competitividade, a espontaneidade e a iniciativa, o que requer práticas educativas menos autoritárias e mais democráticas, conforme salientam Oliveira e Caldana (2004). Como umas das conseqüências deste cenário, Paggi e Guareschi (2004) descrevem a queda da autoridade parental e a prevalência de relações mais permissivas entre adultos e crianças. A questão dos limites surge, então, como uma problemática recorrente nas práticas educativas atuais.

O estabelecimento de limites é, nos dias de hoje, uma das mais inquietantes questões discutidas por profissionais da área da educação e do desenvolvimento infantil. La Taille (1999) observa que, com frequiência, limite é um termo associado à obediência, ao respeito, à retidão moral e à cidadania. Para ele, a palavra sugere, de um lado, fronteira, delimitação entre territórios e, de outro, a possibilidade de transpor e ir além. O autor salienta três dimensões da palavra limites: transpor limites para alcançar a maturidade, respeitá-los em favor da moralidade e, por último, a idéia de construir limites que permitam a preservação da intimidade. No campo da educação, o termo é usado no sentido usual e restritivo e trata daquilo que é permitido ou proibido, em prol da moralidade.

Embora a definição de limites vinculada a um marcador moral envolva a obediência a regras e normas, em um primeiro momento, o significado da moralidade é muito mais amplo. De acordo com La Taille (2001), um ato moral está ligado ao respeito aos direitos alheios, ao cuidado em levar em conta a singularidade e as necessidades do outro e a consideração do bem comum. A construção de limites está, então, diretamente implicada na capacidade da criança de socialização e convivência bem-sucedidas, de forma que ela possa reconhecer e considerar os próprios limites e os dos demais.
Como espaços de convívio social por excelência, a família e a escola desempenham papéis fundamentais no processo de construção dos limites infantis. A família, por ser a primeira instituição social com a qual a criança tem contato, é a sede da socialização, segundo Bem e Wagner (2006). Para as autoras, a família é o espaço no qual os valores e normas sociais são repassados às gerações mais novas. Ainda segundo observam Paggi e Guareschi (2004), é na relação parental que primeiramente se estabelece a noção de limites, o respeito à autoridade e a capacidade de se colocar no lugar do outro.

A escola, por sua vez, além de ser uma instituição responsável pelo desenvolvimento do conhecimento formal, também desempenha um papel importante no estabelecimento dos limites infantis. De acordo com Araújo (2004) e Demo (2002), a aprendizagem escolar, numa perspectiva contemporânea, deve passar pela constituição social e pela preparação para o exercício da cidadania. Estas realizações envolvem não apenas o estabelecimento de limites, mas também a reflexão acerca desses limites. Bruner (2001) escreve a respeito desta constituição social da mente e chama a atenção para o papel da escola na promoção da atividade compartilhada, da reflexão, do diálogo e da negociação no contexto educacional. Segundo o autor, esta seria uma forma de equipar as mentes com habilidades voltadas à compreensão, percepção e ação crítica no mundo social e cultural.

Destarte, escola e família possuem, no estabelecimento dos limites infantis, papéis compartilhados, mas distintos. Pesquisas têm mostrado que não estão claros os papéis da família e da escola no que concerne à educação das crianças e construção de limites (Aquino, 1996). Pais e professores mostram dificuldades em delimitar seus papéis e ações e apresentam muitas dúvidas em relação ao que seja dar limites e possibilidades às crianças. Wagner et al. (2005) descrevem que a tarefa educativa da família passa, atualmente, por um momento de perda de referenciais. Os pais apresentam muitas dúvidas sobre qual a melhor forma de educar os filhos, o que contribui para a dificuldade em estabelecer limites. A escola, por outro lado, depara-se com a falta de limites dos alunos, ou indisciplina, considerada hoje uma das principais dificuldades no cenário escolar. Conforme La Taille (1996), desde a década de 90 a indisciplina é definida pelos professores como ações de desrespeito pelo colega, pelo professor, ou mesmo pela própria instituição 
escolar, trazendo à tona o problema da relação do aluno com um conjunto de normas.

A Teoria das Representações Sociais (Moscovici, 2003), ao investigar as percepções compartilhadas sobre situações sociais, constitui-se como um recurso para entender estas questões. Moscovici (2003) define representação social como um conjunto de conceitos que funciona como uma espécie de teoria de senso comum, orientando práticas e justificando comportamentos de grupos específicos.

Neste trabalho são investigadas as representações sociais que mães e professoras têm sobre limites no desenvolvimento das crianças. $\mathrm{O}$ conhecimento destas representações pode possibilitar o entendimento das crenças e valores subjacentes às práticas educativas empregadas pela família e pela escola na construção dos limites.

\section{MÉTODO}

\section{Participantes}

Participaram deste estudo 14 mães de crianças com idades entre cinco e seis anos que freqüentam a educação infantil em escolas particulares de Porto Alegre. As mães, com idades entre 25 e 44 anos e nível de escolaridade de Ensino Médio completo a pós-graduação, eram de nível socioeconômico médio e residiam na cidade. A ocupação das mães variava desde aquelas que eram apenas donas de casa até as profissionais liberais. Das 14 mães, nove eram casadas, duas eram solteiras e três já separadas dos pais das crianças. Todas respeitaram o critério de coabitação parental. Participaram também oito professoras destas mesmas escolas que trabalham com crianças da faixa etária acima, com idades entre 25 e 40 anos, atuantes na área da Educação Infantil há mais de seis anos. As professoras possuem formação escolar de nível superior incompleto a pós-graduação. As participantes do estudo foram classificadas como de nível socioeconômico médio, considerando-se as escolas participantes e a ocupação profissional das entrevistadas.

\section{Instrumento}

Para a coleta de dados, utilizou-se a entrevista narrativa com as mães e professoras, a qual, segundo Bauer e Jovtchelowitch (1999), possibilita às pessoas reviverem e elaborar vivências. A entrevista narrativa partiu de duas questões: a primeira perguntava pela experiência com limites e a segunda por uma situação marcante na qual houve necessidade de estabelecer limites. As entrevistas foram audiogravadas e posteriormente transcritas para análise.

\section{Delineamento e procedimentos de coleta dos dados}

O estudo é descritivo e nele foram investigadas as representações sociais de mães e de professoras sobre a questão dos limites no desenvolvimento infantil. $\mathrm{O}$ contato com as escolas particulares de Porto Alegre, escolhidas por conveniência, foi realizado através das coordenadoras pedagógicas. Após a anuência das instituições, foi enviada a todas as famílias das crianças da faixa etária escolhida de cada escola uma carta-convite informando sobre a pesquisa e as convidando a participar. $\mathrm{O}$ agendamento das entrevistas com as famílias interessadas e com as professoras foi realizado ou através de contato telefônico, no qual a pesquisadora explicava os objetivos da pesquisa e funcionamento da entrevista, ou através da coordenadora pedagógica. Somente as mães dispuseram-se a participar da pesquisa e comparecer às entrevistas, que foram realizadas individualmente no ambiente escolar, em espaço reservado. $\mathrm{O}$ Termo de Consentimento Livre e Esclarecido foi entregue às participantes, que o assinaram antes da realização das entrevistas.

\section{Análise dos dados}

As entrevistas foram submetidas à análise de conteúdo (Laville \& Dione, 1999). Após a leitura do material das entrevistas, foram identificadas as unidades de análise e as categorias que emergiram dos dados de cada um dos grupos de mães e professoras. A leitura das categorias de cada grupo possibilitou ainda o surgimento dos temas que agruparam as categorias por semelhanças temáticas. Posteriormente à criação de categorias, quantificou-se o número total de vezes em que cada uma delas aparecia nas respostas das participantes, para verificar a freqüência. Os dados das categorias foram descritos através de um texto-síntese e interpretados de acordo com os objetivos previstos. A discussão centrou-se nas categorias que apresentaram maior freqüência. Exemplos das falas das mães e professoras mais ilustrativas de cada categoria serão apresentados nas categorias de maior frequiência.

\section{RESULTADOS}

\section{As narrativas das mães}

Os resultados indicaram três grandes temas no discurso das mães: recursos para construir limites, 
fatores que interferem nos limites e a experiência com limites, cada um com as respectivas categorias.

\section{Recursos para construir limites}

Deste tema emergiram as categorias a seguir dispostas e descritas.

Determinações e estipulações: dizem respeito às narrativas que se referem às rotinas, valores, regras, deveres e hábitos da família que a criança deve respeitar e cumprir.

\begin{abstract}
A família é prioridade. Então final de semana é o único tempo que o pai e a mãe não trabalham que podem estar contigo. Eu não vou abrir mão disso. Tem um aniversário, uma coisa, tudo bem. Bom, durante a semana, aí, queria ir, tudo bem, então tu vai ver teu amigo, mas ainda a gente segura, né? (M6).
\end{abstract}

Diálogo e explicações: referem-se às narrativas que apontam o uso do diálogo, das explicações e negociações para que as crianças possam atender e entender os limites:

Por exemplo, se ela pede para mim: 'Mamãe, deixa eu ficar hoje até mais tarde vendo televisão?', ta, e é um dia de semana e a gente tem como combinação dormir cedo, porque no outro dia eles têm que acordar, ir para o colégio. E daí eu digo: 'Não, filha, hoje não, por causa disso, disso e disso, ela entende numa boa, sabe?' (M9).

Autoridade e imposição: compreendem as narrativas relacionadas às situações nas quais existe a necessidade de se impor e reforçar quem é a autoridade na relação.

Presença e tolerância: abrangem as narrativas relacionadas à necessidade de ser tolerante com algumas atitudes dos filhos, bem como de participar de sua vida e conhecê-los para melhor compreendê-los.

Castigos e sanções: incluem os recursos de retirar algo da criança ou tirá-la de cena para pensar sobre suas atitudes, considerados também recursos extremos.

Palmadas e contenções físicas: dizem respeito às narrativas referentes ao uso de recursos físicos como palmadas e contenções, considerados mais extremos.

Independência e autonomia: referem-se a estratégias que estimulam a independência e ampliam a consciência da criança sobre suas atitudes.

\section{Fatores que interferem nos limites}

Este tema gerou as categorias descritas a seguir.
Culpas e dúvidas: compreendem as reflexões dos pais sobre suas atitudes, Incluindo o sentimento de culpa pelo uso de recursos considerados inadequados e dúvidas quanto a agir de modo correto:

Há um tempo atrás eu acho que também tinha muito meu, assim, porque assim... ah, fases assim da vida pessoal que eu passei assim, de achar assim..., de repente, de eu estar um pouco mais impaciente, de eu estar um pouco mais cansada, isso também influi muito na M.E. (M9).

Escola e colegas: referem-se a modelos e referências oriundos da escola que interferem negativamente na construção dos limites das crianças:

Então, quando ela veio pro colégio, na primeira semana assim, ela não parecia a minha filha. Foi um transtorno, assim, um bum. Mudou completamente, a criança não parecia a mesma, revolucionária, é... Enfrentando, ela tava muito agitada... Então tudo era motivo assim para se alterar, era bem interessante, né? (M13).

A família: diz respeito ao estabelecimento de limites para os filhos, seja através das intromissões dos avós ou dos ex-cônjuges, quando os pais são separados, seja quando as mães relembram a educação recebida de sua família de origem. A afirmação de que os outros filhos são parâmetros na condução dos limites com determinada criança também foi verificada nas entrevistas.

Características das crianças: dizem respeito às narrativas de que as características das crianças, suas capacidades emocionais e cognitivas interferem na construção de limites.

Consumo e modismos: referem-se às preocupações com os estímulos da sociedade que incentivam modismos e consumos.

Outras influências: São os relatos que apontam outras influências na definição de estratégias, como a intuição, trocas com outros pais e literatura.

\section{A experiência com limites}

Do tema $A$ experiência com limites emergiram as categorias descritas a seguir.

Atitudes inconvenientes da criança. são as atitudes das crianças consideradas inconvenientes pelas mães, como a desobediência, as disputas de poder, os choros e reações hostis, que são formas de a criança não atender aos limites propostos: 
Não! É na base da briga com ela, é na base do então vou me atirar no chão e "eu estou de mal contigo, eu não gosto mais de ti" $e$ gritar muitas vezes assim de, de atitudes de birra mesmo (M9).

Preocupação com a moralidade: diz respeito a narrativas referentes à busca da moralidade na construção de limites dos filhos. As mães preocupamse com a noção de respeito ao próximo, a valorização do bem comum e a observância das regras.

Limites desde o início: essa categoria Inclui os relatos que apontam a importância de estabelecer combinações e as regras desde o início com as crianças.

Papéis parentais - é uma categoria relativa a verbalizações que indicam que pai e mãe exercem papéis diferentes na educação dos filhos.

As Tabelas 1, 2 e 3 mostram as frequiências das respostas em cada categoria oriundas das narrativas das mães.

Tabela 1. Distribuição de Freqüência dos Recursos das Mães para Construir Limites

\begin{tabular}{lcc}
\hline Categoria & n & \% \\
\hline Determinações/estipulações & 47 & 25,9 \\
Diálogo/explicações & 46 & 25,4 \\
Autoridade/imposição & 24 & 13,2 \\
Presença/tolerância & 21 & 11,6 \\
Castigos/sanções & 17 & 9,4 \\
Palmadas/contenções & 14 & 7,8 \\
Independência/autonomia & 12 & 6,6 \\
\hline Total & 181 & 100 \\
\hline
\end{tabular}

Tabela 2. Distribuição de Frequiência dos Fatores que Interferem nos Limites Para as Mães

\begin{tabular}{lcc}
\hline Categorias & $\mathbf{n}$ & $\mathbf{\%}$ \\
\hline Culpas/dúvidas & 48 & 27,6 \\
Escola/colegas & 40 & 23 \\
A família & 37 & 21,2 \\
Características das crianças & 34 & 19,5 \\
Consumo/modismos & 8 & 4,5 \\
Outras influências & 7 & 4,0 \\
\hline Total & 174 & 100 \\
\hline
\end{tabular}

Tabela 3. Distribuição de Frequiência das Questões Envolvidas na Experiência com Limites Para as Mães.

\begin{tabular}{lcc}
\hline \multicolumn{1}{c}{ Categorias } & $\mathrm{n}$ & $\%$ \\
\hline Atitudes inconvenientes & 43 & 51,8 \\
Preocupação com moralidade & 21 & 25,3 \\
Limites desde o início & 12 & 14,4 \\
Papéis parentais & 7 & 8,4 \\
\hline \multicolumn{1}{c}{ Total } & 83 & 100 \\
\hline
\end{tabular}

Para estabelecer os limites dos filhos, os recursos mais utilizados pelas mães são as determinações/estipulações (47) e o diálogo/explicações (46). Dentre os fatores que interferem na construção dos limites das crianças, as mães apontam a presença de culpas e dúvidas (48), bem como a influência da escola e dos colegas (40) como aspectos negativos. $\mathrm{Na}$ experiência com o desenvolvimento dos limites dos filhos, sobressaem as atitudes inconvenientes das crianças (43), como manifestações da falta de limites e a preocupação com a moralidade (21).

\section{As narrativas das professoras}

Os resultados indicaram três temas no discurso das professoras: as manifestações da falta de limites, recursos para construir limites e fatores que interferem nos limites.

\section{As manifestações da falta de limites}

O tema Manifestações de falta de limites gerou as categorias descritas a seguir.

Atitudes agressivas: compreendem atitudes impulsivas das crianças como bater e agredir colegas e professores, praticar ofensas ou destruir objetos dos colegas:

\begin{abstract}
Muitos de agressão física, de bater nos colega quando queria disputar brinquedo ou quando era pra lavar a mão ou sair da sala, sempre de forma agressiva e não usando a fala para negociar, pra resolver $(\mathrm{P} 1)$.
\end{abstract}

Não-adesão a rotinas e horários: refere-se às dificuldades das crianças em cumprir as rotinas e horários do espaço escolar e de ter consciência destas regras.

Regressões: incluem atitudes dependentes e regressivas por parte das crianças.

Agitação: são manifestações de agitação e de hiperatividade.

\section{Recursos para construir limites}

O tema Recursos para construir limites gerou as categorias descritas abaixo.

Tolerância e afeto: referem-se às narrativas das professoras que demonstram a necessidade de reagir com afeto e tolerância à falta de limites de seus alunos:

Eu vou tratar com mais atenção, vou estar mais junto, vou dar mais carinho, vou conversar por que que faz, por que que não 
faz. Aí riram, tá passando muito a mão por cima. Eu acho que não (P4).

Diálogo e reflexão: referem-se ao uso do diálogo e questionamentos para estimular o aluno a refletir sobre suas atitudes e colocar-se em outras perspectivas:

Retomo muito com eles: "esse é o combinado? Qual é o combinado? Eu sempre pergunto, sabe? Eu sempre falo assim: "esse é o combinado"? Qual é o combinado?". Aí eles me dizem... Eles sabem te dizer, mas saber, eles sabem (P9).

Troca com os pais: compreende as narrativas relativas à busca dos pais para auxiliar na condução dos limites dos alunos. Esta estratégia serve tanto para conhecer o contexto familiar da criança quanto para falar sobre a escola, buscando a troca com os pais.

Autoridade e imposição: inclui as narrativas relacionadas a momentos nos quais as professoras precisam ser mais impositivas e determinadas com as crianças, reforçar sua autoridade e as regras.

Castigos e sanções: abrangem os relatos de conseqüências de comportamentos considerados inadequados ou sem limites dos alunos, como retirá-lo do contexto ou retirar algo de seu campo de experiência e limitar suas ações.

Interação das crianças com seus pares: referese a situações em que as professoras utilizam-se do grupo e reações dos pares na aprendizagem dos limites das crianças.

Combinações e regras: representam a categoria que inclui as narrativas referentes à importância de construir regras e combinações de convivência no espaço escolar, ao longo do ano.

Livros e profissionais: referem-se a relatos que indicam busca de apoio em livros ou em outros profissionais para embasar a prática e construir limites dos alunos.

Limite espaço-temporal: compreende estratégias para ajudar os alunos a conhecerem a si mesmos e o ambiente e a desenvolver a noção de tempo, de espaço, dos limites de seu corpo e do outro.

\section{Fatores que interferem nos limites}

Deste tema emergiram as categorias a seguir.

Negligência e falta de firmeza dos pais: compreendem as narrativas que relacionam a falta de limites das crianças à falta de firmeza e autoridade dos pais, bem como à ausência, falta de atenção e de cuidados:

É bem complicado, porque o que eu tenho notado nos últimos anos é que eles estão vindo de casa cada vez mais sem limites, os pais não dão os limites necessários. Aí eles querem que nós aqui demos todos no mínimo tempo possível... (P4).

Características das crianças. compreendem as narrativas de que as características das crianças influenciam a construção de limites.

Dúvidas e inseguranças: representam a categoria em que as professoras relatam suas dúvidas $\mathrm{e}$ inseguranças quanto a agir corretamente com seus alunos e momentos nos quais sentem dificuldades para dominar e manter o controle da situação.

Exclusão das crianças: refere-se às reações de excluir do grupo alunos que extrapolam limites as quais interferem nas relações destes alunos.

Falta de apoio das famílias: diz respeito ao relato das professoras de que a falta de parceria das famílias com a escola interfere na construção dos limites em sala de aula.

Vivências e valores docentes: correspondem a relatos de que as experiências pessoais e valores de cada professora interferem na construção dos limites.

Divergências com a escola: constituem uma categoria em que professoras referem a falta de apoio ou diferenças nas concepções relativas à educação entre elas e a escola.

As Tabelas 4, 5 e 6 ilustram as frequiências das respostas em cada categoria, extraídas das narrativas das professoras.

Tabela 4. Distribuição de Frequiência das Manifestações da Falta de Limites Para as Professoras

\begin{tabular}{lcc}
\hline Categorias & $\mathbf{n}$ & $\mathbf{\%}$ \\
\hline Atitudes agressivas & 35 & 53,0 \\
Não adesão rotinas/horários & 18 & 27,3 \\
Regressões & 7 & 10,6 \\
Agitação & 6 & 9,0 \\
\hline Total & 66 & 100 \\
\hline
\end{tabular}

Tabela 5. Distribuição de Freqüência dos Recursos das Professoras Para Construir Limites.

\begin{tabular}{lcc}
\hline Categorias & n & \% \\
\hline Tolerância e afeto & 29 & 20,4 \\
Diálogo e reflexão & 25 & 17,6 \\
Troca com os pais & 23 & 16,0 \\
Autoridade e imposição & 18 & 12,6 \\
Castigos e sanções & 12 & 8,4 \\
Interações com pares & 11 & 7,7 \\
Combinações e regras & 9 & 6,3 \\
Livros e profissionais & 8 & 5,6 \\
Limite espaço-temporal & 7 & 4,9 \\
\hline Total & 142 & 100 \\
\hline
\end{tabular}


Tabela 6. Distribuição de Frequiência dos Fatores que Interferem nos Limites Para as Professoras

\begin{tabular}{lcc}
\hline Categorias & n & \% \\
\hline Negligência/falta de firmeza & 60 & 42,8 \\
Características das crianças & 23 & 16,4 \\
Dúvidas e inseguranças & 21 & 15,0 \\
Exclusões das crianças & 12 & 8,5 \\
Falta de apoio das famílias & 10 & 7,1 \\
Vivências/valores docentes & 7 & 5,0 \\
Divergências com escola & 7 & 5 \\
\hline Total & 140 & 100 \\
\hline
\end{tabular}

As professoras consideram que as atitudes agressivas das crianças (35) e a não-adesão a rotinas e horários (18) são as manifestações mais típicas da falta de limites dos alunos. Para estabelecer os limites, os recursos mais utilizados pelas professoras são tolerância/afeto e diálogo/reflexão (25). Dentre os fatores que interferem na construção dos limites das crianças, a negligência/falta de firmeza dos pais (60) foi a categoria de freqüência mais elevada nas narrativas das professoras.

\section{DISCUSSÃO}

Os resultados desta pesquisa indicam a existência, nas narrativas das participantes, de uma estreita relação entre limites e desenvolvimento moral. Os ideais buscados pelas mães na experiência com limites referem-se à preocupação com a moralidade, que é caracterizada por elas como respeito ao próximo, valorização do bem comum e observância das regras. Nos relatos das mães e professoras, as manifestações da falta de limites e as atitudes consideradas inconvenientes também remetem à questão de desobediência às regras e desrespeito ao outro. Estes dados são apoiados pela literatura (La Taille, 1999), que observa a conotação usual de limites no campo da educação como barreira que não deve ser transposta em prol da moralidade.

Os dados também sugerem que as famílias tendem a construir os limites através do uso de recursos e estratégias. Estas estratégias, chamadas na literatura de práticas educativas, são utilizadas pelos pais para orientar a conduta dos filhos e comunicar o desejo de modificação de comportamentos (Alvarenga \& Piccinini, 2001; Bem \& Wagner, 2006; Ceconello, Antoni \& Koller, 2003). As práticas educativas são classificadas como indutivas e coercitivas. As primeiras são aquelas caracterizadas por apontar à criança as conseqüências de seu comportamento, fazendo-a refletir sobre a situação. Já as estratégias coercitivas envolvem alguma aplicação de força ou poder por parte dos progenitores (Alvarenga \& Piccinini, 2001; Ceconello et al., 2003).

É possível perceber que o uso de estratégias de caráter indutivo, como o diálogo e a tolerância, aparece nas narrativas das mães na mesma proporção em que aparece o uso de recursos considerados coercitivos, como as determinações/estipulações e a imposição de autoridade. Este dado indica tendência das famílias participantes a utilizar práticas educativas alternadas na colocação de limites, que ora podem contemplar a reflexão, ora o uso do poder parental. Apesar da valorização atual de práticas educativas de maior incentivo à autonomia, diálogo e expressão infantil (Oliveira \& Caldana, 2004), a delimitação de regras e imposição de autoridade são também essenciais para crianças desta faixa etária, como observam Piaget (1932/1934) e La Taille (2001). Para estes autores, nesta idade a criança necessita de referências externas, uma vez que não possui condições psicológicas para construir sozinha as regras e as normas de conduta sociais.

É curioso observar que, mesmo com a associação recorrente entre estilos parentais não autoritários e bem-estar infantil (Confalonieri \& Giuliani, 2005; Thompson, Raynor, Cornah, Stevenson \& SonugaBarke, 2001), nesta pesquisa, o uso de punições físicas como, por exemplo, a palmada, apareceu entre as práticas familiares empregadas com as crianças. Estes dados corroboram resultados encontrados em outros estudos (Ceconello et al., 2003; Weber, Viezzer \& Brandemburg, 2004), que demonstraram que as punições físicas ainda são freqüentemente empregadas pelos pais em diferentes países e culturas. Resultados da pesquisa realizada por Pinderhughes, Dudge, Bates, Petit e Zelli (2000) indicaram que altos níveis de estresse associam-se ao uso de medidas disciplinares mais rígidas e a punições físicas. Nas narrativas das mães do presente estudo, as punições físicas são utilizadas exatamente em momentos nos quais elas referem não saber mais como agir ou em situações de estresse. Para Araújo (2004), mesmo diante de novos ideais, a sociedade ainda utiliza recursos autoritários como forma de resolução de conflitos. Para o autor, somente estratégias democráticas, como o diálogo e a reflexão, poderiam contribuir para uma mudança na educação.

Já nas narrativas das professoras são estas estratégias democráticas que prevalecem. Elas privilegiam a negociação, a tolerância, a afetividade e o diálogo. Este fato denota a compreensão de que os limites não são pré-requisitos e de que a criança está em processo de construção de sua autonomia. Dias e Vasconcelos (1999) apontam que tal postura é 
característica de escolas que seguem uma tendência ativa ou democrática. Nestas, a relação professoraluno dá-se de forma menos hierarquizada, priorizamse interesses pessoais e se levam em conta os diferentes estágios do desenvolvimento infantil. O uso da tolerância e afetividade como estratégia mais utilizada pelas professoras deste estudo corrobora os achados de Alves-Mazzotti (2007) e Weber (1996). Estes autores salientam as concepções de docência elaboradas em torno do elemento afetivo e da dedicação, como o exercício de uma tarefa que dá continuidade à função familiar.

Outros estudos afirmam a importância dos valores e metas parentais na escolha das práticas educativas empregadas (Keller et al., 2004) ou a influência do contexto e da cultura (Melendez, 2005; Tudge et al., 2000; Welles-Nystrom, 2005). Não existem dúvidas quanto à contribuição destes fatores na escolha das práticas educativas. Contudo, cumpre considerar outros aspectos que influenciam o uso de determinada prática. As características da criança, por exemplo, foram observadas pelas mães e professoras deste estudo como fatores que interferem na construção dos limites. Alguns autores (Bem \& Wagner, 2006; Dias, 2005; Dias \& Vasconcelos, 1999) ressaltam o papel ativo desempenhado pela criança, que não é apenas um subproduto do meio social. Ela transforma o ambiente e participa ativamente de sua aprendizagem, revalidando o que aprende do adulto. Para as autoras acima, a interiorização dos valores é fruto de uma construção de sentido da própria criança na interação social.

Quando se analisam conjuntamente as narrativas das mães e das professoras, observa-se rivalidade ou falta de parceria entre a escola e família. Para as mães, a escola interfere de forma negativa na construção dos limites dos filhos. Subjacente a estas percepções estaria a desvalorização da instituição escolar e de sua contribuição para o desenvolvimento infantil. Corea e Lewkowicz (2005) falam a respeito da queda de prestígio das instituições cuidadoras, como a escola, por exemplo. Os autores pontuam que muitas escolas estão defasadas em relação à realidade dos alunos, pois atuam em uma lógica diferente da que rege a subjetividade das crianças. Para eles, este aspecto contribuiria para sua desvalorização e perda de espaço social. La Taille (1996) também já destacava, na década de 90, a valorização da individualidade em detrimento da esfera pública. As instituições e funções de caráter público, como a escola, seriam, assim, pouco consideradas na sociedade contemporânea.

Em consonância com este quadro de rivalidade, as professoras, nesta pesquisa, tenderam a responsabilizar as famílias pela falta de limites das crianças. A negligência dos pais e a falta de firmeza são consideradas como as principais causas dos problemas. Na perspectiva das professoras, os pais, com menor disponibilidade para a tarefa educativa, acabam terceirizando esta missão à escola. Estes resultados estão de acordo com os de Cruz (2007) e Macêdo (2001), que identificaram, em seus estudos, que o aluno e a família são apontados pelos professores como os principais culpados pela indisciplina e fracasso escolar. A percepção de que os problemas são oriundos do aluno e de sua família demarca, de acordo com Andrada (2005), ainda uma visão acrítica da instituição escolar, pautada na idéia de aluno-problema. Para essa autora, persistem modelos lineares de causalidade instaurados pela ciência moderna, nos quais as dificuldades escolares são oriundas apenas de problemas individuais, e não de oportunidades sociais e de políticas educacionais.

Nota-se que a falta de limites foi pontuada com freqüência nas histórias narradas por mães e professoras, embora elas pouco tenham mencionado o que seria uma criança com limites. Tais resultados articulam-se com questões sociais contemporâneas, como a falta de modelos e a crise de valores no campo da educação. Para Wagner (2003), passa-se por um momento de perda de referenciais. Em épocas anteriores, as regras, os valores morais e o que se desejava para as crianças eram bem definidos, o que não ocorre na atualidade. Desta forma, os educadores apresentam dificuldades em definir metas e ideais almejados para as crianças. Além disso, sugere-se que a cultura da falta, desencadeada pela sociedade de consumo que estimula a busca constante de bens para superar a insatisfação (Mancebo, Oliveira, Fonseca \& Silva, 2002), contribui para esta tendência atual de desvalorizar o que existe.

Por outro lado, o descontentamento das mães e professoras, implícito na freqüente descrição de atitudes inconvenientes e sem limites das crianças, revelaria ainda a influência da tradição judaico-cristã, que, segundo Araújo (2004), não admite o conflito e a desarmonia. O autor acredita que estas manifestações seriam oportunas para desenvolver na criança a reflexão e a consideração pelos demais. Para ele, aprender a resolver conflitos é um dos caminhos para o desenvolvimento de personalidades morais.

\section{CONSIDERAÇÕES FINAIS}

A presença elevada de culpas e dúvidas nas narrativas das mães e das professoras atesta as dificuldades na educação e construção de limites na 
atualidade. A difusão das teorias psicológicas e pedagógicas, embora tenha trazido muitos benefícios ao desenvolvimento infantil, também trouxe dúvidas e dilemas no que se refere à educação. Por estimularem representações sociais idealizadas de infância e de parentalidade, estas teorias também tornaram os educadores receosos de colocar limites de forma firme, temendo prejudicar a individualidade e a espontaneidade das crianças.

Um dos aspectos mais curiosos do trabalho é a rivalidade que se mostrou existente entre a família e a escola. Sabe-se que o convívio entre estas instâncias nunca foi totalmente harmonioso. Além disso, algumas práticas da família e da escola contribuem para esta relação de animosidade entre as instituições. Por um lado, quando a escola chama a família, na maioria das vezes, é para apontar queixas e dificuldades dos alunos. Por outro lado, a família também tem terceirizado para a escola algumas responsabilidades e, ao mesmo tempo, não repassa a autoridade necessária para tal.

Em face da configuração social em que as crianças ingressam cada vez mais cedo na escola, é difícil pensar que família e escola não exerçam ambas, papel preponderante na construção dos limites. La Taille (1995) observa que a escola completa a socialização que começa no ambiente familiar, onde a criança tem o primeiro contato com o mundo das regras e dos valores. Para o autor, a escola, por se constituir em importante espaço para trocas sociais, deve preparar os alunos para o convívio, para a adaptação ao espaço público e para o exercício da cidadania. Destarte, no desenvolvimento moral das crianças, família e escola têm papéis diferenciados, mas complementares.

\section{REFERÊNCIAS}

Alvarenga, P., \& Piccinini, C. (2001). Práticas educativas maternas e problemas de comportamento em pré-escolares. Psicologia Reflexão e Crítica, 14(3), 449-460.

Alves-Mazzotti, A. J. (2007). Processos formadores da representação social do ser professor. [Resumo]. Trabalho apresentado na $V$ Jornada Internacional e III Conferência Brasileira sobre Representações Sociais, Brasília, Brasil.

Andrada, E. (2005). Novos paradigmas na prática do psicólogo escolar. Psicologia Reflexão e Crítica, 18(2), 196-199.

Aquino, J. C. (1996). A desordem na relação professor-aluno: indisciplina, moralidade e conhecimento. Em J. C. Aquino (Org.), Indisciplina na escola: alternativas teóricas e práticas (pp. 3956). São Paulo: Summus.

Araújo, U. (2004). Assembléia escolar: um caminho para a resolução de conflitos. São Paulo: Moderna.
Bauer, M., \& Jovchelovitch, S. (1999). A questão da metodologia em pesquisa: texto, imagem e materiais sonoros. Tese não publicada. Programa de Extensão Pós-graduação em Psicologia da Pontifícia Universidade Católica, RS.

Bem, L., \& Wagner, A. (2006). Reflexões sobre a construção da parentalidade e o uso de estratégias educativas em famílias de baixo nível socioeconômico. Psicologia em Estudo, 11(1), 63-71.

Bruner, J. (2001). A cultura da educação. Porto Alegre: Artmed.

Ceconello, A., Antoni, C., \& Koller, S. (2003). Práticas educativas, estilos e abuso físico no contexto familiar. Psicologia em Estudo, 8(número especial), 45-54.

Confalonieri, E., \& Giuliani, C. (2005). Parental child-rearing practices and psychological adjustment of pre-school children. [Resumo]. Eta-Evolutiva, 82, 67-73. Recuperado em 05 de maio, de 2007 em www.periodicos.capes.gov.br

Corea, C., \& Lewkowics, I. (2005). Pedagogia del aburrido: Escuelas destituídas, famílias perplejas. Buenos Aires: Paidós.

Cruz, F. M. (2007). Os significados da exclusão escolar no fracasso em matemática. [Resumo]. Trabalho apresentado na $V$ Jornada Internacional e III Conferência Brasileira sobre Representações Sociais, Brasília, Brasil.

Demo, P. (2002). O desafio reconstrutivo-político da aprendizagem. Em P. Demo (Org.), Grandes Pensadores em Educação (pp. 0733). Porto Alegre: Mediação.

Dias, A. (2005). Educação moral e autonomia na educação infantil: o que pensam os professores. Psicologia Reflexão e Crítica, 18(3), 370-380.

Dias, A. A., \& Vasconcellos, V. M. (1999). Concepções de autonomia dos educadores infantis. Temas em Psicologia, 1(7), 9-21.

Keller, H., Yovsi, R., Borke, J., Kartner, J., Jensen, H., \& Papaligoura, Z. (2004). Developmental consequences of early parenting experiences: Self-recognition and self-regulation in three cultural communities. Child Development, 75, 1745-1760.

La Taille, Y. (1995). Educação moral: família e escola. Dois pontos, 3(11), 99-94.

La Taille, Y. (1996). A indisciplina e o sentimento de vergonha. Em J. C. Aquino (Org.), Indisciplina na escola: alternativas teóricas $e$ práticas (pp. 09-24). São Paulo: Summus.

La Taille, Y. (1999). Limites: três dimensões educacionais. São Paulo: Ática.

La Taille, Y. (2001). Desenvolvimento moral: a polidez segundo as crianças. Cadernos de Pesquisa, 114, 89-119.

Laville, C., \& Dionne, J. (1999). A construção do saber. Porto Alegre: Artes Médicas.

Macêdo, R. M. (2001). Indisciplina em sala de aula: representações sociais do professor (Resumo). Em C. M. Nascimento-Schulze \& B. V. Camargo (Orgs.), Caderno de Resumos da II Jornada Internacional sobre Representações Sociais (p.59). Florianópolis, Brasil: JIRS.

Mancebo, D., Oliveira, D., Fonseca, J., \& Silva, L. (2002). Consumo e subjetividade: trajetórias teóricas. Estudos de Psicologia, 7(2), 325-332.

Melendez., L. (2005). Parental beliefs and practices around early selfregulation: The impact of culture. Infants \& Young Children, 18, 136-146.

Moscovici, S. (2003). Representações Sociais. Petrópolis: Vozes. 
Oliveira, T. T., \& Caldana, R. H. (2004). Mães psicólogas ou psicólogas mães: vicissitudes na educação dos filhos. Estudos de Psicologia, 9(3), 585-593.

Paggi, K., \& Guareschi, P. (2004). O desafio dos limites: um enfoque psicossocial na educação dos filhos. Rio de Janeiro: Vozes.

Piaget, J. (1932/1994). O juízo moral na criança. São Paulo: Summus.

Pinderhughes, E., Dudge, K., Bates, J. E., Petit, G. S., \& Zelli, A. (2000). Discipline responses: Influences of parents socioeconomic status, ethnicity, beliefs about parenting, stress and cognitiveemotional process. Journal of family psychology, 14(3), 380-400.

Thompson, M. J. J.; Raynor, A.; Cornah, D.; Stevenson, J., \& SonugaBarke, S. (2001). Parenting behavior described by mothers in a general population sample. Child: Care, health and development, 28(2), 149-155.

Tudge, J., Hayes, S., Doucet, F., Kulakova, N., Tammeveski, P., Meltsas, M., \& Lee, S. (2000). Parent's participation in cultural practices with their preschoolers. Psicologia: Teoria e Pesquisa, 16(1), 1-10.

Wagner, A. (2003). A família e a tarefa de educar: algumas reflexões a respeito das famílias tradicionais frente as demandas modernas.
Em T. Feres-Carneiro (Org), Família e casal: arranjos $e$ demandas contemporâneas (pp. 27-33). Rio de Janeiro: Ed. PUCRio.

Wagner, A, Predebon, J., \& Falcke, D. (2005). Transgeracionalidade e educação: como se perpetua a família? Em A. Wagner (Org.), Como se perpetua a família? (pp. 93-106). Porto Alegre: Edipucrs.

Weber, S. (1996). O professorado e o papel da educação na sociedade. Campinas: Papirus.

Weber, L.; Viezzer, A. \& Brandenburg, O. (2004). O uso de palmadas e surras como práticas educativas. Estudos de Psicologia, 9(2), 227-237.

Welles-Nystrom, B. (2005). Co-sleeping as a window into Swedish culture: considerations of gender and health care. Scandinavian Journal of Caring Sciences, 19(4), 354-360.

Recebido em 31/08/2007 Aceito em 14/07/2008

Endereço para correspondência : Greicy Boness de Araujo, Rua Mariz e Barros nº 62/301, CEP: 90690390, Porto Alegre-RS, Brasil.E-mail: greboness@hotmail.com 